\title{
Association between body mass index and fragility fracture in postmenopausal women: a cross-sectional study using Korean National Health and Nutrition Examination Survey 2008-2009 (KNHANES IV)
}

Jihan Kim ${ }^{1,2}$, Sami Lee ${ }^{2^{*}} \mathbb{D}$, Sung Soo Kim², Jong-Pyo Lee ${ }^{3}$, Jong Sung Kim², Jin Gyu Jung ${ }^{2}$, Seok Jun Yoon², Kyu Pil Kim ${ }^{4}$, Chan-Keol Park ${ }^{5}$ and Yong-Hwan Kim ${ }^{6}$

\begin{abstract}
Background: The present study examined the relationship between body mass index (BMI) and the risk for fragility fractures in postmenopausal Korean women.

Methods: Among subjects who participated in the 4th Korea National Health and Nutrition Examination Survey (2008-2009), 2114 women $\geq 40$ years of age were included. BMI was based on standards set by the Korean Society for the Study of Obesity, as follows: $<18.5 \mathrm{~kg} / \mathrm{m}^{2}$, underweight; $18.5 \leq$ to $<25 \mathrm{~kg} / \mathrm{m}^{2}$, normal weight; and $\geq 25 \mathrm{~kg} / \mathrm{m}^{2}$, obese. Subjects were also divided into three groups according to the location of fragility fracture: spine, hip, or wrist.

Results: The mean $( \pm S D)$ rate of fragility fracture was significantly different among the three groups: $5.9 \pm 2.9 \%$ (underweight), $1.1 \pm 0.3 \%$ (normal weight), and $3.0 \pm 0.7 \%$ (obese) $(p=0.001)$. After correcting for age, family history, and treatment history of osteoporosis and rheumatoid arthritis, smoking and drinking status, and level of exercise, multivariable regression analysis revealed that the odds ratio for fragility fracture in the underweight group was 5.48 [95\% confidence interval (CI) 1.80-16.73] and $3.33(95 \% \mathrm{Cl} 1.61-6.87)$ in the obese group. After subdividing fragility fractures into vertebral and non-vertebral, the odds ratio for vertebral fracture in the underweight group was 5.49 (95\% Cl 1.31-23.09) times higher than that in the normal weight group; in the obese group, the non-vertebral fracture odds ratio was 3.87 (95\% Cl 1.45-10.33) times higher. Analysis of non-vertebral fractures in the obese group revealed an odds ratio for fracture $22.05(95 \% \mathrm{Cl} 1.33-365.31)$ times higher for hip fracture and 3.85 (95\% Cl 1.35-10.93) times higher for wrist fracture.
\end{abstract}

Conclusions: Obesity and underweight increased the risk for fragility fractures in postmenopausal Korean women. Keywords: Body mass index, Obesity, Osteoporosis, Osteoporotic fractures, Postmenopausal

*Correspondence: smlee@cnuh.co.kr

${ }^{2}$ Department of Family Medicine, Research Institute for Medical Science,

Chungnam National University School of Medicine, 282 Munhwa-ro, Jung-Gu, Daejeon 35015, Korea

Full list of author information is available at the end of the article

\section{Background}

Osteoporosis is a musculoskeletal disorder characterized by a decrease in bone density and abnormal changes in bone microstructure [1]. It is one of the most common diseases in postmenopausal women due to the agerelated reduction in estrogen levels. Individuals with 
osteoporosis have a higher risk for fragility fractures due to reduced bone density, and increased risk for resulting complications and mortality rates [2]. Fragility fracture refers to a non-traumatic fracture and, according to the World Health Organization (WHO), is defined as a fracture caused by a fall from a level below one's height, including fracture(s) caused by impact that do not cause fracture(s) in normal bones, and even when that impact is not recognized [3]. In Korea, women aged $>50$ (59.5\%) are more likely to experience fragility fractures in their lifetime than men $>50(23.8 \%)$ years of age [4]. Therefore, in Korea, the National Health Examination Program, under the National Health Insurance Service, was designed for women aged 54 and 66 to undergo testing for bone mineral density in the lumbar spine to diagnose, treat, and manage diseases related to osteoporosis.

One of the most common changes experienced by postmenopausal women is weight gain. Compared with premenopausal women, postmenopausal women exhibit a $20 \%$ increase in fat mass, especially in central adiposity [5]. In general, it is common for postmenopausal women to exhibit a decrease in bone density with age; however, weight gain has been reported to help maintain bone density [6]. Therefore, weight loss was believed to increase the risk for fragility fracture due to a reduction in bone density while, conversely, an increase in body weight would maintain bone density and eventually prevent fragility fracture. However, in recent years, it has been considered important to not simply observe a change in weight but rather a change in muscle mass. Therefore, increase in body weight-not due to muscle mass, but to body fat-could increase the risk for osteoporosis [7]. In fact, studies including Korean women have demonstrated that high body fat mass can increase the risk for bone density reduction in the femoral neck [8]. In another study including postmenopausal women, the optimal body mass index (BMI) with minimal risk for osteoporosis was $23-24.9 \mathrm{~kg} / \mathrm{m}^{2}$ [9]. As such, weight gain is no longer believed to prevent osteoporosis.

Although several studies have investigated the relationship between obesity and osteoporosis in Koreans, only a few have examined the impact of obesity on fragility fractures. Accordingly, this study aimed to investigate the relationship between BMI-an index of obesity-and fragility fractures in postmenopausal Korean women.

\section{Methods}

\section{Participants}

The Korean National Health and Nutrition Examination Survey is a statutory survey addressing the health behavior, prevalence of chronic disease, and food and nutrition intake of Korean by the Korea Centers for Disease Control and Prevention and is a government-designated statistic based on Article 17 of the Statistics Act (Approval No. 117002). It corresponds to research conducted by the government for public welfare in accordance with the Bioethics Act. The original survey data are freely accessible without any administrative permission as open-access resources through the website of the Korea Centers for Disease Control and Prevention (https://www.knhan es.cdc.go.kr) [10].

A total of 11,604 women registered in the 4th National Health and Nutrition Examination Survey (2008-2009) were selected as primary participant group. Of these, 3023 were postmenopausal, $\geq 40$ years of age, and had available bone density test data, and were selected as the secondary participant group. After exclusion of 909 women with uncertain examination records, 2114 were ultimately included as the final participant group (Fig. 1).

\section{Definitions and measurements}

BMI was determined by dividing body weight $(\mathrm{kg})$ by height $\left(\mathrm{m}^{2}\right)$. Based on the WHO standards for the Western Pacific region and Korean Society for the Study of Obesity standards, $\mathrm{BMI}<18.5 \mathrm{~kg} / \mathrm{m}^{2}$ was defined as underweight, $18.5 \leq$ to $<25 \mathrm{~kg} / \mathrm{m}^{2}$ as normal weight, and $\geq 25 \mathrm{~kg} / \mathrm{m}^{2}$ as obese [11]. In the present study, those classified as overweight, with BMI $23 \leq$ to $<25 \mathrm{~kg} / \mathrm{m}^{2}$, were allocated to the normal weight group according to the National Health and Nutrition Examination Survey questionnaire.

Fragility fractures were defined as non-traumatic or low-traumatic fractures caused by the impact of a fall below one's height [12]. For fragility fractures, responses to the question "Have you experienced fragility fractures?", were divided into sites such as the "spine," "hip," and "wrist," with responses "Yes," "No," "Not Applicable," and "I don't know." Those who responded "I don't know" were already excluded during the selection process. "Yes" refers to people diagnosed with osteoporosis or osteopenia through bone mineral density tests such as dualenergy X-ray absorptiometry (DXA) and experienced fractures. "No" refers to the group diagnosed with osteoporosis or osteopenia through tests, but didn't experience fractures. "Not applicable" refers to the group who were not diagnosed with bone related disease through tests and did not experience fractures as well. Since it was necessary to determine the presence or absence of a fracture in this study, those who responded with "No" and "Not Applicable" were allocated to the same group with no fragility fractures. Participants who responded with "Yes" to any of the three sites were classified into a group with fragility fractures.

Bone density in the participants was measured using DXA and a fan-beam densitometer (Discovery, Hologic Inc., Bedford, MA, USA), and the lumbar spine and left 


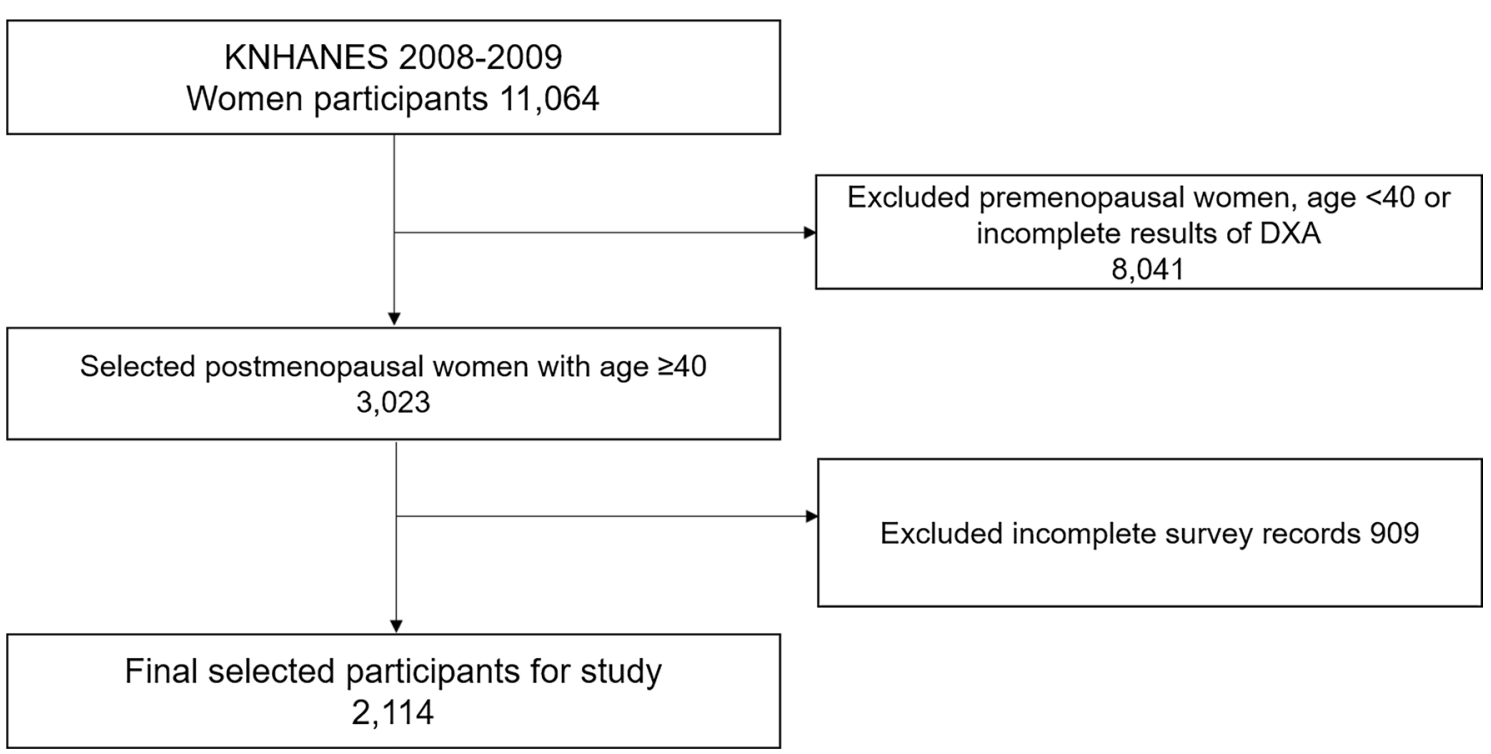

Fig. 1 Study population. KNHANES, Korean National Health and Nutrition Examination Survey; DXA, Dual-energy X-ray absorptiometry

femur were measured. The units of bone density were area density, $\mathrm{g} / \mathrm{cm}^{2}$. In addition, according to the osteoporosis diagnostic criteria set by the WHO, those with T-score $>-1.0$ were classified as normal, T-score $>-2.5$ and $\leq-1.0$ as osteopenia, and T-score $\leq-2.5$ as osteoporosis [13].

In the smoking questionnaire, current smokers refer to those who have smoked 100 or more cigarettes in a lifetime and continue to smoke at the time of the survey. Former smokers refer to those who smoked 100 or more cigarettes in the past and have not continued to smoke at the time of the survey. Non-smokers refer to those who have never smoked at least 100 cigarettes in their lifetime [14]. For alcohol status, considering the guidelines for moderate drinking of Koreans, the frequency of drinking from the question "Drinking frequency in a year" and the amount from the question "Amount you drink at a time" were both considered. Those who do not drink at all were classified as "non-drinkers," those $\geq 65$ years of age and who consumed $<2$ glasses per week, or $<65$ years of age and consumed $<4$ glasses per week as "moderate drinkers," and the remainder as "heavy drinkers" [15]. The moderate exercise was classified based on the questionnaire about whether one exercises moderately for $\geq 30 \mathrm{~min}$ at least five times per week.

Waist circumference was measured to the nearest under $0.1 \mathrm{~cm}$ using SECA 200, a measuring tape, during whole exhalation at the horizontal plane midway between the lower end of the rib and the iliac crest, at the mid-axillary line [16].

\section{Statistical analysis}

During the analysis of data from the National Health and Nutrition Examination Survey, the following errors were corrected through the complex sample design: inclusion errors due to differences in the number of households and populations between the sample design period and the survey period; unequal selection probabilities; and nonresponse error of those who did not participate in the survey. For this, the primary sampling unit, k-strata, and weight were specified [17].

Participants were divided into three groups according to BMI: underweight, normal weight, and obese. The complex samples general linear model was used for continuous variables such as age, height, waist circumference, age at menopause, and bone density (BMC, T-score) for mean comparison. For categorical variables, such as fragility fracture rate, treatment history and family history of osteoporosis, history of rheumatoid arthritis, smoking status, drinking status, and moderate exercise, Rao-Scott chi-square test was used.

Complex samples logistic regression was used to analyze the relationship between BMI and fragility fracture rate. During analysis, variables that could affect fragility fractures such as age, treatment history and family history of osteoporosis, history of rheumatoid arthritis, smoking status, drinking (i.e., alcohol) status, and moderate exercise, were corrected.

All statistical analyses in this study were performed using SPSS version 22 (IBM Corporation, Armonk, NY, USA). 


\section{Results}

\section{General characteristics of the participants}

The mean $( \pm S D)$ age of the normal weight group was $59.01 \pm 0.42$ years, which was not statistically different from the mean age of the underweight group $(61.43 \pm 3.00$ years) but was significantly different from that of the obese group $(60.98 \pm 0.44$ years) $(p=0.001)$. Among body composition items, mean height was not different among the three groups; however, weight, BMI, and waist circumference were different from the normal weight group. The mean weight of the normal, underweight, and obese groups was $53.62 \pm 0.21 \mathrm{~kg}, 41.43 \pm 1.05 \mathrm{~kg}$, and $64.65 \pm 0.28 \mathrm{~kg}$, respectively; the differences were statistically significant (underweight, $p<0.001$; obese, $p<0.001$ ). The mean BMI of the normal, underweight, and obese groups was $22.49 \pm 0.06 \mathrm{~kg} / \mathrm{m}^{2}, 17.55 \pm 0.20 \mathrm{~kg} / \mathrm{m}^{2}$, and $27.31 \pm 0.09 \mathrm{~kg} / \mathrm{m}^{2}$, respectively (underweight group, $p<0.001$; obese group, $p<0.001)$. The mean waist circumferences of the normal, underweight, and obese groups were $76.96 \pm 0.29 \mathrm{~cm}, 65.30 \pm 0.86 \mathrm{~cm}$, and $89.47 \pm 0.37 \mathrm{~cm}$, respectively, which was significantly different from the normal weight group (underweight group, $p<0.001$; obese, $p<0.001$ ). The average age at menopause was not different among the groups (normal weight, $48.59 \pm 0.22$ years; underweight, $45.61 \pm 1.66$ years; obese, $48.48 \pm 0.26$ years). The average weight-corrected appendicular skeletal muscle mass was $34.29 \pm 0.37$ for normal weight group, $49.43 \pm 3.35$ for underweight group, and $28.52 \pm 0.33$ for the obese group, with the underweight group and the obese group showing statistically significant difference compared to the normal weight group (each $p<0.001)$. In case of bone density $\left(\mathrm{g} / \mathrm{cm}^{2}\right)$, the average bone density of the femoral neck $(0.79 \pm 0.03)$ and the entire femur $(0.94 \pm 0.03)$ in the underweight group was significantly higher than that of the normal weight group (femoral neck average, $0.73 \pm 0.01$; femur average $0.88 \pm 0.01$ ) (each $p=0.035, p=0.029$ ) In the case of T-score, only the average T-score of the femoral neck in the underweight group $(-0.35 \pm 0.24)$ was significantly different from that of the normal weight group $(-0.87 \pm 0.06)(p=0.032)$. Regarding fragility fracture rate, there were differences among the three groups: underweight, $5.9 \% \pm 2.9$; normal, $1.1 \pm 0.3 \%$; and obese, $3.0 \pm 0.7 \%(p=0.001)$. In the smoking status, there was a difference in the proportion of non-smoker, former smoker and current smoker in the three groups $\left(p=0.043, x^{2}=11.863\right)$. There were no statistical differences in treatment history and family history of osteoporosis, history of rheumatoid arthritis, drinking status, and moderate exercise among the three groups (Table 1).

\section{Difference between vertebral and non-vertebral fracture rate} according to BMI via Rao-Scott chi-squared test

The overall fragility fracture rates for the underweight, normal weight, and obese groups were $5.9 \%, 1.1 \%$, and $3.0 \%$, respectively, and the difference was statistically significant $\left(p=0.001, x^{2}=11.186\right)$. When fracture rates were compared between the vertebral and nonvertebral fracture rates, vertebral fracture rate for the underweight group $(4.5 \pm 2.6 \%)$ was significantly higher compared with the normal weight group $(0.6 \pm 0.2 \%)$ and obese group $(0.9 \pm 0.4 \%)\left(p=0.014, \chi^{2}=7.644\right)$. In the case of non-vertebral fracture rate, that of the obese group $(2.3 \pm 0.6 \%)$ was relatively higher than that of the normal weight group $(0.7 \pm 0.3 \%)$ and underweight group $(1.4 \pm 1.4 \%)$, with a statistically significant difference among the three groups $\left(p=0.011, \chi^{2}=8.040\right)$ (Fig. 2).

\section{Odds ratio for fragility fracture according to multiple logistic regression analysis}

The odds ratio for fragility fracture in the underweight and obese groups was compared with the normal weight group via multiple logistic regression analysis. In model 1 , which was not corrected, the odds ratio for fracture in the underweight group was 5.48 (95\% CI 1.66-17.76) and 2.72 (95\% CI 1.38-5.37) in the obese group. In model 2, which was corrected for age and family history and treatment history of osteoporosis, odds ratio for the underweight group was 5.14 (95\% CI 1.77-14.93) and 3.12 (95\% CI 1.50-6.48) in the obese group. In model 3, which was corrected for age, family history and treatment history of osteoporosis, history of rheumatoid arthritis, smoking status, drinking status, and moderate exercise, the odds ratio for the underweight group was 5.48 (95\% CI 1.8016.73) and 3.33 (95\% CI 1.61-6.87) for the obese group (Table 2).

Fragility fractures were classified as vertebral and nonvertebral fractures, and logistic regression analysis was performed after correcting for age, family history and treatment history of osteoporosis, history of rheumatoid arthritis, smoking status, drinking status, and moderate exercise. In the underweight group, the odds ratio for vertebral fracture was 5.49 (95\% CI 1.31-23.09) times higher than that of the normal weight group. In the obese group, there was no statistically significant difference in the odds ratio for vertebral fracture, while the non-vertebral fracture odds ratio was observed to be 3.87 (95\% CI 1.45-10.33) times higher. When non-vertebral fractures were compared after dividing them into hip and wrist, the obese group had an odds ratio for hip fracture 22.05 (95\% CI 1.33-365.31) times higher and 3.85 (95\% CI 1.35-10.93) times higher for wrist fracture (Table 3). 
Table 1 Characteristics for postmenopausal women according to BMI

\begin{tabular}{|c|c|c|c|c|}
\hline & $\begin{array}{l}\text { Underweight } \\
(\mathrm{BMI}<18.5)\end{array}$ & $\begin{array}{l}\text { Normal } \\
(\mathrm{BMI} \geq 18.5 \text { and }<25)\end{array}$ & $\begin{array}{l}\text { Obesity } \\
(\mathrm{BMI} \geq 25)\end{array}$ & $\begin{array}{l}p \text { value } \\
\left(x^{2}\right)\end{array}$ \\
\hline & $\mathrm{N}=45$ & $N=1234$ & $N=835$ & \\
\hline Est. number $(n)(\%)$ & $105,855(2.1 \%)$ & $3,030,556(60.6 \%)$ & $1,867,253(37.3 \%)$ & \\
\hline Age (years) & $61.43 \pm 3.00$ & $59.01 \pm 0.42$ & $60.98 \pm 0.44^{b}$ & \\
\hline Height (cm) & $153.36 \pm 1.61$ & $154.28 \pm 0.22$ & $153.77 \pm 0.28$ & \\
\hline Weight (kg) & $41.43 \pm 1.05^{c}$ & $53.62 \pm 0.21$ & $64.65 \pm 0.28^{c}$ & \\
\hline BMI $\left(\mathrm{kg} / \mathrm{m}^{2}\right)$ & $17.55 \pm 0.20^{c}$ & $22.49 \pm 0.06$ & $27.31 \pm 0.09^{c}$ & \\
\hline Waist circumference $(\mathrm{cm})$ & $65.30 \pm 0.86^{c}$ & $76.96 \pm 0.29$ & $89.47 \pm 0.37^{c}$ & \\
\hline Menopausal age (years) & $45.61 \pm 1.66$ & $48.59 \pm 0.22$ & $48.48 \pm 0.26$ & \\
\hline Weight-adjusted ASM & $49.43 \pm 3.35^{c}$ & $34.29 \pm 0.37$ & $28.52 \pm 0.33^{c}$ & \\
\hline \multicolumn{5}{|l|}{$\mathrm{BMD}\left(\mathrm{g} / \mathrm{cm}^{2}\right)$} \\
\hline Lumbar spine total & $0.92 \pm 0.03$ & $0.90 \pm 0.01$ & $0.91 \pm 0.01$ & \\
\hline Femur neck & $0.79 \pm 0.03^{\mathrm{a}}$ & $0.73 \pm 0.01$ & $0.72 \pm 0.01$ & \\
\hline Femur total & $0.94 \pm 0.03^{\mathrm{a}}$ & $0.88 \pm 0.01$ & $0.88 \pm 0.01$ & \\
\hline \multicolumn{5}{|l|}{ BMD (T-score) } \\
\hline Lumbar spine total & $-0.80 \pm 0.22$ & $-0.91 \pm 0.06$ & $-0.88 \pm 0.06$ & \\
\hline Femur neck & $-0.35 \pm 0.24^{\mathrm{a}}$ & $-0.87 \pm 0.06$ & $-0.89 \pm 0.06$ & \\
\hline Femur total & $0.31 \pm 0.18$ & $-0.03 \pm 0.05$ & $-0.07 \pm 0.06$ & \\
\hline Fragility fracture (\%) & $5.9( \pm 2.9)$ & $1.1( \pm 0.3)$ & $3.0( \pm 0.7)$ & $0.001(11.186)$ \\
\hline Treatment of OP (\%) & & & & 0.369 \\
\hline None & $91.8( \pm 3.6)$ & $91.4( \pm 1.0)$ & $93.2( \pm 1.1)$ & (1.938) \\
\hline Current treatment & $8.2( \pm 3.6)$ & $8.6( \pm 1.0)$ & $6.8( \pm 1.1)$ & \\
\hline FHx of osteoporosis (\%) & & & & 0.540 \\
\hline No & $78.3( \pm 8.0)$ & $85.1( \pm 1.3)$ & $86.0( \pm 1.6)$ & (1.859) \\
\hline Yes & $21.7( \pm 8.0)$ & $14.9( \pm 1.3)$ & $14.0( \pm 1.6)$ & \\
\hline Rheumatoid arthritis (\%) & & & & 0.156 \\
\hline No & $94.0( \pm 3.7)$ & $96.3( \pm 0.6)$ & $94.3( \pm 0.9)$ & $(3.835)$ \\
\hline Yes & $6.0( \pm 3.7)$ & $3.7( \pm 0.6)$ & $5.7( \pm 0.9)$ & \\
\hline Smoking status (\%) & & & & 0.043 \\
\hline Non-smoker & $76.7( \pm 7.8)$ & $90.4( \pm 1.0)$ & $91.8( \pm 1.1)$ & $(11.863)$ \\
\hline Former smoker & $9.6( \pm 5.0)$ & $5.2( \pm 0.7)$ & $3.8( \pm 0.7)$ & \\
\hline Current smoker & $13.7( \pm 6.6)$ & $4.4( \pm 0.7)$ & $4.4( \pm 0.9)$ & \\
\hline Alcohol consumption (\%) & & & & 0.242 \\
\hline Non-drinker & $65.4( \pm 9.3)$ & $52.4( \pm 1.6)$ & $49.1( \pm 2.2)$ & (8.583) \\
\hline Moderate drinker & $23.9( \pm 7.5)$ & $40.4( \pm 1.6)$ & $44.6( \pm 2.3)$ & \\
\hline Heavy drinker & $10.8( \pm 7.6)$ & $7.2( \pm 0.9)$ & $6.3( \pm 1.1)$ & \\
\hline Moderate exercise (\%) & & & & 0.264 \\
\hline Yes & $6.9( \pm 4.1)$ & $12.8( \pm 1.3)$ & $15.4( \pm 1.9)$ & (3.855) \\
\hline No & $93.1( \pm 4.1)$ & $87.2( \pm 1.3)$ & $84.6( \pm 1.9)$ & \\
\hline
\end{tabular}

All values are weighted value and presented mean ( \pm standard deviation) or percent ( \pm standard deviation)

$\mathrm{a}, \mathrm{b}$ and $\mathrm{c}$ are presented $p$ value $<0.05,<0.01$ and $<0.001$, respectively

$B M I$ body mass index, $A S M$ appendicular skeletal muscle mass, $B M D$ bone mineral density, OP osteoporosis, FHx familial history

\section{Discussion}

The purpose of this study was to investigate the relationship between BMI and fragility fracture(s) in postmenopausal Korean women. In both the underweight and obese groups, the fragility fracture rates were 5.48 and 3.33 times higher, respectively, compared with the normal weight group. In particular, the underweight group exhibited an odds ratio for vertebral fracture that was 5.49 times higher, and the obese group exhibited an odds ratio for non-vertebral fracture that was 3.87 times 


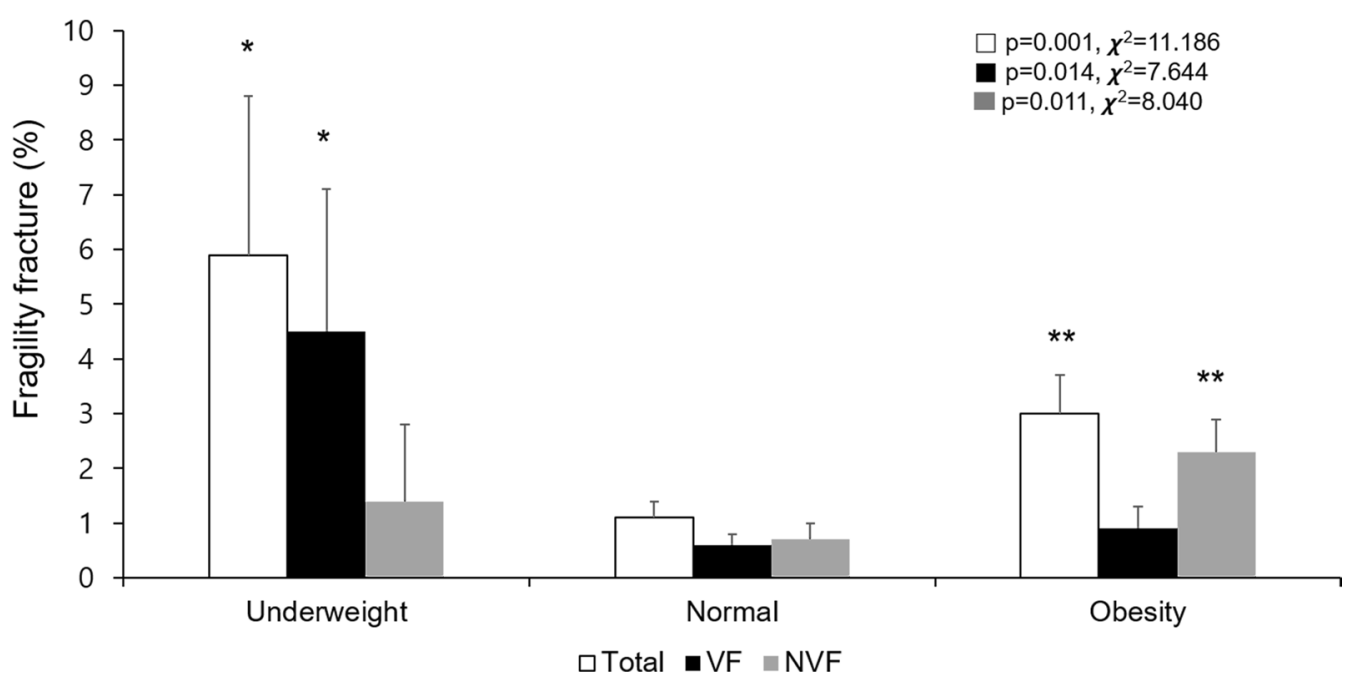

Fig. 2 Prevalence of fragility fracture according to body mass index. * and ** means $p<0.05$ and $p<0.01$ compared to normal BMI by Rao-Scott chi-square test. VF vertebral fracture, NVF non-vertebral fracture, BMI body mass index

Table 2 Odds ratio (OR) of fragility fracture for postmenopausal women by multivariate logistic regression analysis

\begin{tabular}{lc}
\hline & OR $\mathbf{( 9 5 \% ~ C l )}$ \\
\hline Normal weight $(\mathrm{BMI} \geq 18.5$ and $<25)$ & 1 (Reference) \\
Underweight $(\mathrm{BMI}<18.5)$ & \\
Model 1 & $5.48(1.66-17.76)$ \\
Model 2 & $5.14(1.77-14.93)$ \\
Model 3 & $5.48(1.80-16.73)$ \\
Obesity (BMI $\geq 25)$ & \\
Model 1 & $2.72(1.38-5.37)$ \\
Model 2 & $3.12(1.50-6.48)$ \\
Model 3 & $3.33(1.61-6.87)$ \\
\hline
\end{tabular}

Model 1: Crude

Model 2: Adjusted for age, family history of OP and treatment of OP

Model 3: Adjusted for age, family history of OP, treatment of OP, presence of rheumatoid arthritis, smoking status, alcohol consumption and moderate exercise

$B M /$ body mass index, $O P$ osteoporosis higher. As such, the most significant finding of the present study was that postmenopausal women who were underweight or obese exhibited higher rates of fragility fracture(s).

The findings of high fragility fracture rate in the underweight group were consistent with previous studies; however, there were slight differences in fracture sites for each study. According to one study, underweight individuals with a $\mathrm{BMI}<20 \mathrm{~kg} / \mathrm{m}^{2}$ demonstrated a hip fracture rate twice as high as those with a BMI of $25 \mathrm{~kg} /$ $\mathrm{m}^{2}$ [18]. Another study found that for individuals with a $\mathrm{BMI}<20 \mathrm{~kg} / \mathrm{m}^{2}$, the non-vertebral fracture rate was 2.45 times higher [19]. The reason for this is that the risk for falls increases with lower BMI [20]. However, previous studies have shown that lower weight increases lumbar spine fractures, similar to the results of the present investigation. One study found that the decrease in BMI increased the vertebral fracture rate [21]. Other studies reported that lumbar spine fracture rate was 2.79 times

Table 3 Odds ratio (OR) of vertebral fracture (VF) and non-vertebral fracture (NVF) according to BMI

\begin{tabular}{|c|c|c|c|c|}
\hline & \multirow{3}{*}{$\begin{array}{l}\text { VF } \\
\text { OR }(95 \% \mathrm{Cl}) \\
\text { Total }\end{array}$} & \multicolumn{3}{|l|}{ NVF } \\
\hline & & \multicolumn{3}{|l|}{ OR $(95 \% \mathrm{CI})$} \\
\hline & & Total & Hip & Wrist \\
\hline Underweight (BMI < 18.5) & $5.49(1.31-23.09)$ & $1.83(0.22-15.60)$ & $10.65(0.38-295.97)$ & $2.02(0.24-17.29)$ \\
\hline Normal (BMI $\geq 18.5$ and <25) & 1 (Reference) & 1 (Reference) & 1 (Reference) & 1 (Reference) \\
\hline Obesity $(\mathrm{BMI} \geq 25)$ & $1.89(0.59-6.00)$ & $3.87(1.45-10.33)$ & $22.05(1.33-365.31)$ & $3.85(1.35-10.93)$ \\
\hline
\end{tabular}

Adjusting for age, family history of osteoporosis, treatment of osteoporosis, presence of rheumatoid arthritis, smoking status, alcohol consumption and moderate exercise

$B M I$ body mass index 
higher for underweight individuals with $\mathrm{BMI}<18.5 \mathrm{~kg} /$ $\mathrm{m}^{2}$ compared to those with $\mathrm{BMI}>24 \mathrm{~kg} / \mathrm{m}^{2}$ [22]. Studies have reported that the reason for high fragility fracture rate in underweight individuals is related to muscle loss. According to one study, sarcopenia is associated with older age, low BMI, and low bone density [23]. Although this explains the increase in fragility fracture rate [24], items for diagnosing sarcopenia were omitted in this study; as such, an accurate comparison could not be made.

In this study, there was no statistical difference in the rate of lumbar spine fractures in the obese group, which was similar to other previous studies. One study that examined changes in lumbar spine bone density in individuals with weight changes showed that individuals with weight gain had increased lumbar spine bone density compared to those with weight loss [25]. As a result, we can predict that as weight increases, spinal bone density increases, and the fracture rate decreases. Another study showed that high BMI and waist circumference in women were associated with a decrease in bone density due to increase in fat mass; however, whether these factors affect the lumbar spine fracture rate needs further study [26].

Recently, it was reported that obesity is related to the site of fragility fractures. One study found that obesity led to lower risk of lumbar and femur fractures [18]; however, another study showed that obesity increased the non-vertebral fracture rate. In particular, the proximal humerus fracture rate was 1.28 times higher, the femur fracture rate was 1.7 times higher, and the ankle fracture rate was 1.5 times higher $[27,28]$. Another study reported that high BMI led to a decrease in the relative risk for fragility fracture in the spine, hip, and wrist, but an increase in fragility fractures of the ankle [29]. In postmenopausal women, obesity led to an increase in humerus fracture rates [30]. As such, one reason why obesity is associated with fractures could be that high body fat levels can reduce bone density. One study reported that the bone loss effect in the entire hip and the femoral neck was more prominent in Korean middle-age women with normal weight and a body fat percentage $\geq 36 \%$ [31].

The non-vertebral fracture rate was higher in the obese group, unlike the underweight group, which could be explained by the fact that the obese group exhibited significantly lower weight-corrected appendicular skeletal muscle mass compared with the normal weight group. Appendicular skeletal muscle mass is used as one metric to define sarcopenia [32], and it is common to use height-corrected appendicular skeletal muscle mass. However, the reason for comparing weight-corrected appendicular skeletal muscle mass in this study was based on a study in which Korean women with height-corrected appendicular skeletal muscle mass demonstrated a poor correlation with age-related muscle mass reduction; therefore, it was necessary to use weight-corrected appendicular skeletal muscle mass [33]. According to one study, sarcopenia with reduced appendicular skeletal muscle mass was associated with a decrease in bone density [34]. Although this decrease in bone density may be directly related to fractures, it is also possible that the risk for falls is increased due to a decrease in appendicular skeletal muscle mass [35].

Generalizing the results of the present investigation would be difficult given some following points. First, it was a cross-sectional study limited to postmenopausal women. Second, it was unclear when the BMD test performed and when the fracture occurred. Third, the BMI might have been calculated relatively high due to a decrease in height if there were a single or multiple vertebral fractures in the past. Further studies are required to consider the association between fragility fractures and other obesity indices such as waist circumference or waist to hip ratio as well as BMI. Fourth, the overweight group was inevitably included in the normal weight group for analysis because accurate analysis was difficult due to data limitations. Fifth, the percentage of underweight was only $2 \%$ of the total study population. As a relatively small number of people were classified as underweight, the general bone density characteristics of the group did not appear, and it is thought that the individual subjects' bone density characteristics were more reflected. This should be studied further through future researches.

\section{Conclusions}

In conclusion, despite the various limitations, the most significant finding of this study was that underweight and obesity increased the rate of fragility fractures in postmenopausal women. In the end, there are various factors that affect fragility fractures, so further research will be needed, but the this study showed the impact of the body mass index.

\section{Abbreviations}

BMI: Body mass index; WHO: World health organization.

\section{Acknowledgements}

None.

\section{Authors' contributions}

JK: contributions to the conception, acquiring, analyzing and interpreting data, drafting the manuscript; SL: conceiving and designing this study, analyzing and interpreting the data, revising the manuscript; CKP, YHK: contributions to the conception and acquiring the data; SSK, JPL, KPK: contributions to the conception and interpreting the data; JSK, JGJ, SJY: contributions to the conception and revising the manuscript. All authors have read and approved the submitted version. All authors have agreed to take personal responsibility for their contributions. All authors read and approved the final manuscript. 


\section{Funding}

None.

\section{Availability of data and materials}

The original datasets used and analyzed during the current study are publicly available for academic purposes in the KNHANES website (http://knhanes.cdc. go.kr or https://knhanes.cdc.go.kr/knhanes/eng/index.do).

\section{Ethics approval and consent to participate}

The National Health and Nutrition Examination Survey, conducted under Article 16 of the National Health Promotion Act, is a statutory survey addressing the health behavior, prevalence of chronic disease, and food and nutrition intake of Korean citizens, and is a government-designated statistic based on Article 17 of the Statistics Act (Approval No. 117002). The survey was conducted every three years from the first (1998) to the third (2005) period. After its reorganization into an annual survey system, it has been conducted annually from the fourth period (2007-2009). It corresponds to research conducted by the government for public welfare in accordance with the Bioethics Act. The original survey data are freely accessible without any administrative permission as open-access resources through the website of the Korean Centers for Disease Control and Prevention (https://knhanes.cdc.go.kr). The National Health and Nutrition Examination Survey was conducted with the approval of the Institutional Review Board of Korea Centers for Disease Control and Prevention (Reference numbers 2008-04EXP-01-C and 2009-01CON-03-2C). Informed consent was obtained from every participant at the time when the surveys were conducted. The present study was approved for waiver of review by the Chungnam National University Hospital Institutional Review Board (Daejeon, South Korea; Institutional Review Board number: 2020-04-102).

\section{Consent for publication}

None.

\section{Competing interests}

None.

\section{Author details}

${ }^{1}$ Department of Family Medicine, Sejong Trinium Woman's Hospital, Sejong, Korea. ${ }^{2}$ Department of Family Medicine, Research Institute for Medical Science, Chungnam National University School of Medicine, 282 Munhwa-ro, Jung-Gu, Daejeon 35015, Korea. ${ }^{3}$ Department of Obstetrics and Gynecology, Sejong Trinium Woman's Hospital, Sejong, Korea. ${ }^{4}$ Department of Family Medicine, Chungnam National University Sejong Hospital, Sejong, Korea. ${ }^{5}$ Division of Rheumatology, Department of Internal Medicine, Chungnam National University Sejong Hospital, Sejong, Korea. ${ }^{6}$ Department of Orthopedic Surgery, Chungnam National University Hospital, Daejeon, Korea.

Received: 23 June 2020 Accepted: 3 February 2021

Published online: 09 February 2021

\section{References}

1. Kim J, Kim B, Lee H, Choi H, Won C. The relationship between prevalence of osteoporosis and proportion of daily protein intake. Korean J Fam Med. 2013;34(1):43-8.

2. Moon JH, Kim LO, Kim HJ, Kong MH. Evaluation of the predictive index for osteoporosis as a clinical tool to identify the risk of osteoporosis in Korean men by using the Korea National Health and Nutrition Examination Survey data. Korean J Fam Med. 2016:37(6):346-50.

3. World Health Organization. Guidelines for preclinical evaluation and clinical trials in osteoporosis. Geneva: World Health Organization; 1998.

4. Park C, Ha YC, Jang S, Jang S, Yoon HK, Lee YK. The incidence and residual lifetime risk of osteoporosis-related fractures in Korea. J Bone Miner Metab. 2011;29(6):74451.

5. Ley CJ, Lees B, Stevenson JC. Sex- and menopause-associated changes in body-fat distribution. Am J Clin Nutr. 1992;55(5):950-4.

6. Park HA, Kim HJ, Kim TJ, Park JJ, Park JK. Weight and bone mineral density -The summary of epidemiological evidence. Korean J Fam Med. 2009;30:167-74.

7. Tomlinson DJ, Erskine RM, Morse Cl, Onambélé GL. Body fat percentage, body mass index, fat mass index and the ageing bone: their singular and combined roles linked to physical activity and diet. Nutrients. 2019;11(1):E195.

8. Kim J, Kwon $\mathrm{H}$, Heo BK, et al. The Association between fat mass, lean mass and bone mineral density in premenopausal women in Korea: a crosssectional study. Korean J Fam Med. 2018;39(2):74-84.

9. Lee JH, Kim JH, Hong AR, Kim SW, Shin CS. Optimal body mass index for minimizing the risk for osteoporosis and type 2 diabetes. Korean J Intern Med. 2019;30:1432-42.

10. Korea Centers for Disease Control and Prevention. The 4th Korea National Health and Nutrition Examination Survey (KNHANES IV) (2008-2009). In. Seoul, Korea: Korea Centers for Disease Control and Prevention; 2009.

11. Na YM, Park HA, Kang JH, et al. Obesity, obesity related disease, and disability. Korean J Fam Med. 2011;32(7):412-22.

12. Johnell O, Kanis JA. An estimate of the worldwide prevalence and disability associated with osteoporotic fractures. Osteoporos Int. 2016;17:1726.

13. Kanis JA, Melton LJ III, Christiansen C, Johnston CC, Khaltaev N. The diagnosis of osteoporosis. J Bone Miner Res. 1994;9:1137-41.

14. Jung JG, Wu LT, Kim JS, Kim ED, Yoon SJ. Relationship between smoking and abdominal aorta calcification on computed tomography. Korean J Fam Med. 2019;40(4):248-53.

15. Lee S, Kim JS, Jung JG, Oh MK, Chung TH, Kim J. Korean alcohol guidelines for moderate drinking based on facial flushing. Korean J Fam Med. 2019;40(4):204-11.

16. Seo WJ, Lee GM, Hwang JH, Lee MN, Kang HC. Association between body mass index, waist circumference and prevalence of microalbuminuria in Korean adults of age 30 years and older without diabetes, hypertension, renal failure, or overt proteinuria: The 2013 Korean National Health and Nutrition Examination Survey. Korean J Fam Med. 2016;37(1):57-63.

17. Kim Y. The Korea National Health and Nutrition Examination Survey (KNHANES): current status and challenges. Epidemiol Health. 2014;36:e2014002.

18. De Laet C, Kanis JA, Odén A, et al. Body mass index as a predictor of fracture risk: a meta-analysis. Osteoporos Int. 2005;16(11):1330-8.

19. Deloumeau A, Moltó A, Roux C, Briot K. Determinants of short term fracture risk in patients with a recent history of low-trauma non-vertebral fracture. Bone. 2017;105:287-91.

20. Szewieczek J, Mazur K, Wilczyński K. Geriatric falls in the context of a hospital fall prevention program: Delirium, low body mass index, and other risk factors. Clin Interv Aging. 2016;11:1253-61.

21. Zvekic-Svorcan J, Aleksic J, Jankovic T, et al. Capture the vertebral fracture: risk factors as a prediction. J Back Musculoskelet Rehabil. 2019;32(2):269-76.

22. Chen $\mathrm{YL}$, Liu YC, Wu CH, et al. Role of BMl and age in predicting pathologic vertebral fractures in newly diagnosed multiple myeloma patients: a retrospective cohort study. Hematol Oncol. 2018;36(2):407-15.

23. Wang WF, Lin CW, Xie CN, et al. The association between Sarcopenia and osteoporotic vertebral compression refractures. Osteoporos Int. 2019;30(12):2459-67.

24. Sarcopenia WJ. Clin Geriatr Med. 2017;33(3):305-14.

25. Lee HR, Hong SS, Lee SY, et al. The impact of body weight change on bone mineral density of the lumbar spine in perimenopausal women: a retrospective, one-year follow-up study. Korean J Fam Med. 2011;32(4):219-25.

26. Luo J, Lee RY. How does obesity influence the risk of vertebral fracture? Findings from the UK Biobank participants. JBMR Plus. 2020;4(5):e10358.

27. Compston JE, Watts NB, Chapurlat R, et al. Obesity is not protective against fracture in postmenopausal women: GLOW. Am J Med. 2011;124(11):1043-50.

28. Prieto-Alhambra D, Premaor MO, Fina Aviles F, et al. The association between fracture and obesity is site-dependent: a population-based study in postmenopausal women. J Bone Miner Res. 2012;27(2):294-300.

29. Compston JE, Flahive J, Hosmer DW, et al. GLOW Investigators. Relationship of weight, height, and body mass index with fracture risk at different sites in postmenopausal women: the Global Longitudinal study of Osteoporosis in Women (GLOW). J Bone Miner Res. 2014;29(2):487-93.

30. Mpalaris V, Anagnostis P, Goulis DG, lakovou I. Complex association between body weight and fracture risk in postmenopausal women. Obes Rev. 2015;16(3):225-33.

31. Kim DH, Lim H, Chang S, Kim JN, Roh YK, Choi MK. Association between body fat and bone mineral density in normal-weight middle-aged Koreans. Korean J Fam Med. 2019:40(2):100-5. 
32. Chen LK, Woo J, Assantachai P, et al. Asian Working Group for Sarcopenia: 2019 consensus update on sarcopenia diagnosis and treatment. J Am Med Dir Assoc. 2020;21(3):300-307.e2.

33. Kim YS, Lee Y, Chung YS, et al. Prevalence of sarcopenia and sarcopenic obesity in the Korean population based on the Fourth Korean National Health and Nutritional Examination Surveys. J Gerontol A Biol Sci Med Sci. 2012;67(10):1107-13.

34. Go SW, Cha YH, Lee JA, Park HS. Association between sarcopenia, bone density, and health-related quality of life in Korean men. Korean J Fam Med. 2013;34(4):281-8
35. National Institute for Health and Care Excellence (UK). Osteoporosis: assessing the risk of fragility fracture. In: National Institute for Health and Care Excellence: Clinical Guidelines. 2017. Available from: https://www. nice.org.uk/guidance/cg146.

\section{Publisher's Note}

Springer Nature remains neutral with regard to jurisdictional claims in published maps and institutional affiliations.
Ready to submit your research? Choose BMC and benefit from:

- fast, convenient online submission

- thorough peer review by experienced researchers in your field

- rapid publication on acceptance

- support for research data, including large and complex data types

- gold Open Access which fosters wider collaboration and increased citations

- maximum visibility for your research: over $100 \mathrm{M}$ website views per year

At BMC, research is always in progress.

Learn more biomedcentral.com/submissions 